\title{
Boron-Lined Neutron Detector Measurements
}
AT Lintereur
RT Kouzes
JH Ely
LE Erikson
ER Siciliano

November 6, 2009

\section{Pacific Northwest}

NATIONAL LABORATORY

Proudly Operated by Battelle Since 1965 


\title{
DISCLAIMER
}

This report was prepared as an account of work sponsored by an agency of the United States Government. Neither the United States Government nor any agency thereof, nor Battelle Memorial Institute, nor any of their employees, makes any warranty, express or implied, or assumes any legal liability or responsibility for the accuracy, completeness, or usefulness of any information, apparatus, product, or process disclosed, or represents that its use would not infringe privately owned rights. Reference herein to any specific commercial product, process, or service by trade name, trademark, manufacturer, or otherwise does not necessarily constitute or imply its endorsement, recommendation, or favoring by the United States Government or any agency thereof, or Battelle Memorial Institute. The views and opinions of authors expressed herein do not necessarily state or reflect those of the United States Government or any agency thereof.

\author{
PACIFIC NORTHWEST NATIONAL LABORATORY \\ operated by \\ BATTELLE \\ for the \\ UNITED STATES DEPARTMENT OF ENERGY \\ under Contract DE-AC05-76RL01830
}

Printed in the United States of America
Available to DOE and DOE contractors from the Office of Scientific and Technical Information,
P.O. Box 62, Oak Ridge, TN 37831-0062;
ph: (865) 576-8401
fax: $(865)$ 576-5728
email: reports@adonis.osti.gov

\begin{abstract}
Available to the public from the National Technical Information Service, U.S. Department of Commerce, 5285 Port Royal Rd., Springfield, VA 22161 ph: (800) 553-6847 fax: $(703) 605-6900$ email: orders@ntis.fedworld.gov online ordering: http://www.ntis.gov/ordering.htm
\end{abstract}

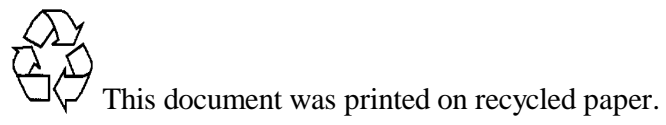


PNNL-18938

\title{
Boron-Lined Neutron Detector Measurements
}

\author{
AT Lintereur \\ RT Kouzes \\ JH Ely \\ LE Erikson \\ ER Siciliano
}

November 6, 2009

Pacific Northwest National Laboratory

Richland, Washington 99352 


\section{Executive Summary}

Radiation portal monitors used for interdiction of illicit materials at borders include highly sensitive neutron detection systems. The main reason for having neutron detection capability is to detect fission neutrons from plutonium. The currently deployed radiation portal monitors (RPMs) from Ludlum and Science Applications International Corporation (SAIC) use neutron detectors based upon ${ }^{3} \mathrm{He}$-filled gas proportional counters, which are the most common large neutron detector. There is a declining supply of ${ }^{3} \mathrm{He}$ in the world, and thus, methods to reduce the use of this gas in RPMs with minimal changes to the current system designs and sensitivity to cargo-borne neutrons are being investigated.

Four technologies have been identified as being currently commercially available, potential alternative neutron detectors to replace the use of ${ }^{3} \mathrm{He}$ in RPMs. These technologies are:

1) Boron trifluoride $\left(\mathrm{BF}_{3}\right)$-filled proportional counters,

2) Boron-lined proportional counters,

3) Lithium-loaded glass fibers, and

4) Coated non-scintillating plastic fibers.

Reported here are the results of tests of a newly designed boron-lined proportional counter option. This testing measured the neutron detection efficiency and gamma ray rejection capabilities of a system manufactured by GE Reuter Stokes.

Results indicate that the boron-lined neutron detector prototype, with an active surface area of $0.305 \mathrm{~m}$ by $1.75 \mathrm{~m}$ (12" $\mathrm{x} 69$ ") or $0.5345 \mathrm{~m}^{2}$, had an efficiency that is $72 \%$ of a single ${ }^{3} \mathrm{He}$ tube in the current RPM polyethylene moderator box. The intrinsic gamma efficiency (rejection factor) was found to be on the order of $10^{-6}$ at an exposure rate of $10 \mathrm{mR} / \mathrm{hr}$ from a ${ }^{60} \mathrm{Co}$ source, which meets the requirement for this parameter. The GARRn value at $10 \mathrm{mR} / \mathrm{hr}$ is $1.01(1)$, which is within the required window. The system shows significant promise, and testing of the next evolution of this detector design will show if all of the neutron detection requirements can be met. 


\section{Acronyms and Abbreviations}

ANSI

ASP

Atm

CBP

cps

DOE

GARRn

MCNP

$\mathrm{mR}$

$\mathrm{Pa}$

PNNL

PolyBox

POV

psi

PVT

RPM

RSP

SAIC
American National Standards Institute

Advanced Spectroscopic Portal

atmospheres

Customs and Border Protection

counts per second

U.S. Department of Energy

Gamma Absolute Rejection Ratio in the presence of neutrons

Monte Carlo for Neutrons and Photons Transport Code

milli-Roentgen

Pascal

Pacific Northwest National Laboratory

polyethylene moderator/reflector box

personally owned vehicle

pounds per square inch

Polyvinyl Toluene (plastic) scintillation gamma detector

Radiation Portal Monitor

Radiation Sensor Panel

Science Applications International Corporation 


\section{Contents}

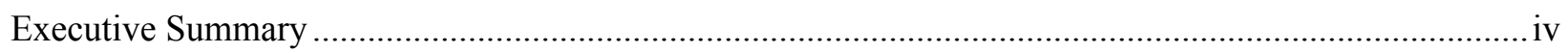

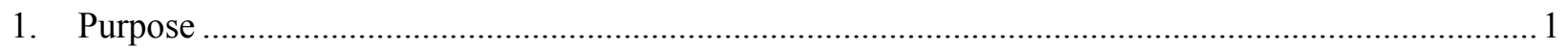

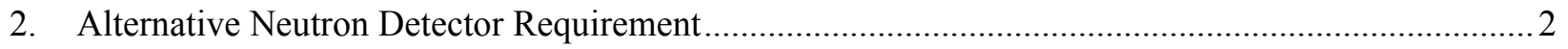

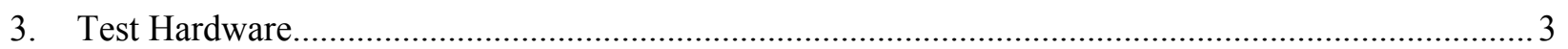

3.1. GE Reuter Stokes Prototype Neutron Detector ........................................................................ 3

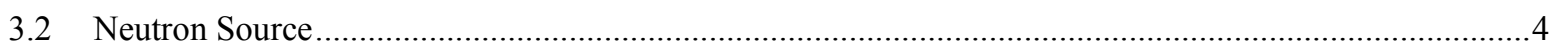

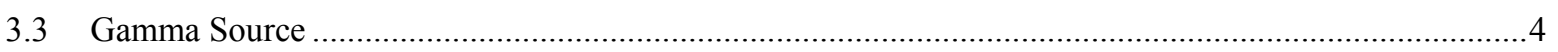

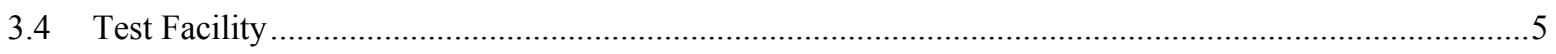

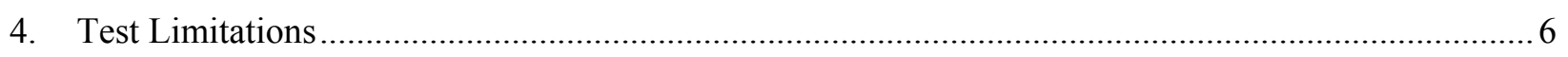

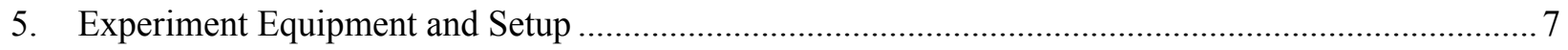

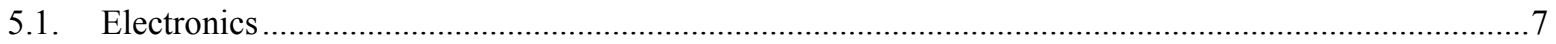

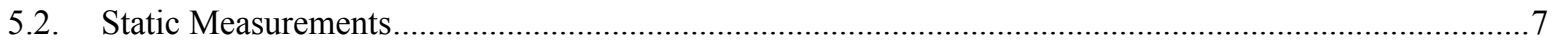

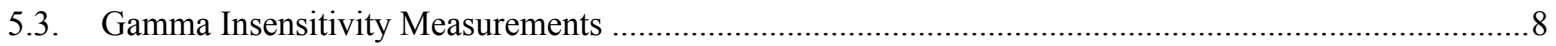

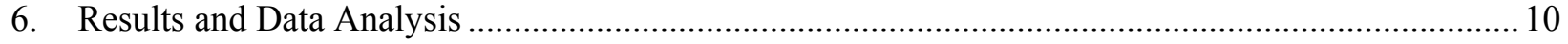

6.1. Modeling Results...................................................................................................................

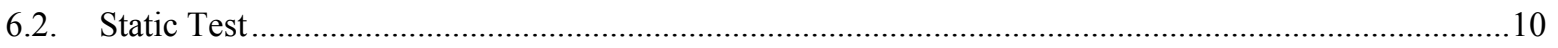

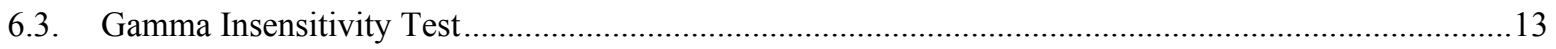

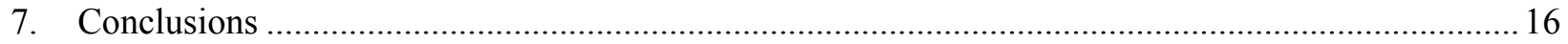

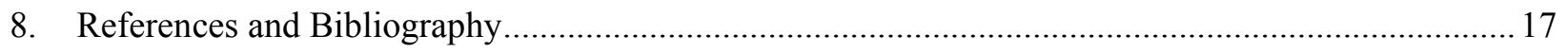




\section{Figures and Tables}

\section{Figures}

Figure 3.1: View of the GE Reuter Stokes detector (right side) in an RPM Radiation Sensor Panel........... 3

Figure 3.2: GE Reuter Stokes external detector electronics used in the testing....................................... 4

Figure 5.1: GE Reuter Stokes detector assembly positioned for static tests outside of the SAIC shroud. ... 8

Figure 5.2: GE Reuter Stokes detector positioned for testing with the gamma ray and neutron sources..... 9

Figure 6.1: Modeling result (a) for response of a single two-inch diameter boron-lined tube to neutrons, and the experimental result for the response of the multi-tube GE Reuter Stokes prototype detector

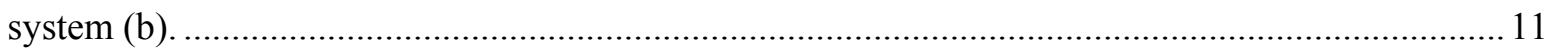

Figure 6.2: Count rate obtained with the GE Reuter-Stokes detector prototype..................................... 12

Figure 6.3: Net count rate obtained with the front and back layer of detectors for different test configurations with the moderated and bare source.............................................................. 12

Figure 6.4: Neutron efficiency of the GE Reuter-Stokes detector system under different test scenarios compared to one ${ }^{3} \mathrm{He}$ tube in the SAIC polyethylene moderating box........................................... 13

Figure 6.5: Response of boron lined tubes to ${ }^{60} \mathrm{Co}$ gamma rays on the left and scaled to show neutron

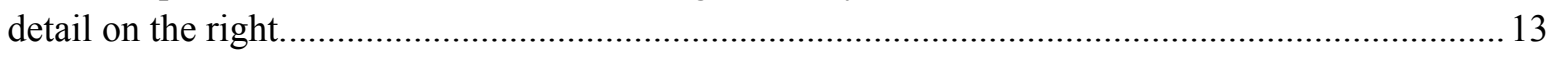

Figure 6.6: Response of ${ }^{3} \mathrm{He}$ tubes operated with external electronics to ${ }^{60} \mathrm{Co}$ gamma rays on the left and scaled to show detail on the right.

\section{Tables}

Table 5.1: Exposure rate versus distance for the gamma ray source at Building 318 .

Table 6.1: Neutron counts recorded with the boron-lined tubes in the presence of high exposure gamma field.

Table 6.2: Estimated number of photons incident on the active area of the detector calculated with both the source strength and an effective activity for each of the exposure rates.

Table 6.3: Estimates of the Absolute Efficiency, GARRn and the Intrinsic Gamma Ray Rejection Factor for the different gamma exposure rates. 


\section{Purpose}

Radiation portal monitor (RPM) systems used for interdiction of illicit materials at borders include highly sensitive neutron detection systems. The main reason for having neutron detection capability is to detect fission neutrons from plutonium. The currently deployed radiation portal monitors from Ludlum and Science Applications International Corporation (SAIC) use neutron detectors based upon ${ }^{3} \mathrm{He}$-filled gas proportional counters, which are the most common large neutron detector.

Within the last few years, the amount of ${ }^{3} \mathrm{He}$ available for use in gas proportional counter neutron detectors has become more restricted, while the demand has significantly increased, especially for homeland security applications (Kouzes 2009). In the near future, the limited supply is expected to curtail the use of ${ }^{3} \mathrm{He}$; therefore, alternative neutron detection technologies are being investigated for use in the radiation portal monitor systems being deployed for border security applications (Van Ginhoven 2009).

From a survey of technologies, only four technologies have been identified as currently commercially available, potential alternative neutron detectors to replace the use of ${ }^{3} \mathrm{He}$ in RPMs in the near-term. These technologies are:

1) Boron trifluoride $\left(\mathrm{BF}_{3}\right)$-filled proportional counters (from $\mathrm{LND}$ ),

2) Boron-lined proportional counters (from GE Reuter Stokes or LND),

3) Lithium-loaded glass fibers (from NucSafe), and

4) Coated non-scintillating plastic fibers (from IAT).

Reported here are the results of tests of a newly designed boron-lined proportional counter option. This testing measured the neutron detection efficiency and gamma ray rejection capabilities of a system manufactured by GE Reuter Stokes.

The purpose of this testing was to measure the efficiency of the GE Reuter Stokes prototype neutron detection system to determine if this technology can meet the specified neutron detection requirements. The measurements made as part of this testing included:

1) response of the system with the original moderation configuration provided by GE Reuter Stokes to moderated and unmoderated neutrons

2) response of the system to moderated and unmoderated neutrons with added moderation to the front of the detector

3) response of the system to a high gamma-ray exposure rate with and without a neutron source. 


\section{Alternative Neutron Detector Requirement}

Boron-lined proportional counters are a possible neutron detector replacement technology for ${ }^{3} \mathrm{He}-$ filled tubes. These tubes, with moderation, were designed to fit in the space available to the currently deployed SAIC RPM polyethylene box [0.114 m deep x $0.304 \mathrm{~m}$ wide x $2.180 \mathrm{~m}$ tall $(4.5 \mathrm{in} . \times 12 \mathrm{in} . \times 85.7 \mathrm{in}$.)] that has an active surface area of $0.663 \mathrm{~m}^{2}$, which contains the ${ }^{3} \mathrm{He}$ tubes. The GE Reuter Stokes detector tested had an active detector surface area, including moderator, of $0.535 \mathrm{~m}^{2}$. The difference in active surface areas was due to the space required for the GE Reuter Stokes electronics. Pacific Northwest National Laboratory (PNNL) has tested the GE Reuter Stokes boron-lined prototype neutron detection system.

The SAIC systems were purchased under a specification (Stromswold et al., 2003) that requires a single radiation sensor panel (RSP) to meet the following requirements:

"A ${ }^{252} \mathrm{Cf}$ neutron source will be used for testing neutron sensor sensitivity:

- To reduce the gamma-ray flux, the source shall be surrounded by at least $0.5 \mathrm{~cm}$ of lead. To moderate the neutron spectrum, $2.5 \mathrm{~cm}$ of polyethylene shall be placed around the source.

- The absolute detection efficiency for such a ${ }^{252} \mathrm{Cf}$ source, located $2 \mathrm{~m}$ perpendicular to the geometric midpoint of the neutron sensor, shall be greater than $2.5 \mathrm{cps} / \mathrm{ng}$ of ${ }^{252} \mathrm{Cf}$. The neutron detector center shall be $1.5 \mathrm{~m}$ above grade for this test. (Note: 10 nanograms of ${ }^{252} \mathrm{Cf}$ is equivalent to 5.4 micro-Ci or $2.1 \times 10^{4} \mathrm{n} / \mathrm{s},{ }^{1}$ since ${ }^{252} \mathrm{Cf}$ has a $3.092 \%$ spontaneous fission (SF) branch and 3.757 neutrons/SF.)

- The neutron detector shall not generate alarms due to the presence of strong gamma-ray sources. The ratio of neutron sensor gamma-ray detection efficiency to neutron detection shall be less than 0.001."

To evaluate the performance of alternate neutron detectors compared to what is currently deployed three criteria are considered: 1) neutron absolute detection efficiency, 2) intrinsic efficiency of gammas detected as neutrons, and 3) Gamma Absolute Rejection Ratio in the presence of neutrons (GARRn) (Kouzes et al., 2009).

The neutron absolute detection efficiency $\left(\epsilon_{\mathrm{abs} n}\right)$ required was previously specified $(2.5 \mathrm{cps} / \mathrm{ng}$ from a ${ }^{252} \mathrm{Cf}$ source at $2 \mathrm{~m}$ in a specified pig) as listed above. The intrinsic efficiency of gamma rays detected as neutrons $\left(\epsilon_{\text {int } \gamma \mathrm{n}}\right)$ is the number of events that are counted as neutrons in the presence of a gamma ray source divided by the number of photons hitting the active detector area, and shall be less than $10^{-6}$ at an exposure rate of $10 \mathrm{mR} / \mathrm{hr}$. The GARRn is the number of events that are counted as neutrons $\left(\epsilon_{\mathrm{abs} \gamma \mathrm{n}}\right)$ in the presence of both gamma and neutron sources divided by the neutron count rate in the presence of the neutron source only; the requirement for this parameter is that $0.9<\mathrm{GARRn}<1.1$ at a $10 \mathrm{mR} / \mathrm{h}$ gamma exposure rate.

In addition, these systems are required to meet all aspects of the ANSI N42.35 standard (ANSI 2004). A summary of neutron detection systems in RPMs can be found in a PNNL report (Kouzes et al., 2007).

\footnotetext{
${ }^{1} 2.3 \times 10^{4} \mathrm{n} / \mathrm{s}$ is the currently used value
} 


\section{Test Hardware}

\subsection{GE Reuter Stokes Prototype Neutron Detector}

The GE Reuter Stokes boron-lined detector that was tested is a new prototype design that utilizes multiple boron-lined proportional counters in a moderator assembly instead of a single two-inch tube as previously produced. Thermal neutrons react with the ${ }^{10} \mathrm{~B}$ resulting in charged particles from the ${ }^{10} \mathrm{~B}(\mathrm{n}, \alpha)^{7} \mathrm{Li}$ reaction that subsequently produce a signal in the proportional counter. The goal of the prototype development is to produce an assembly with comparable efficiency to a single ${ }^{3} \mathrm{He}$ tube in the SAIC RPM. The assembly of boron-lined proportional counters from GE Reuter Stokes came enclosed in a polyethylene moderator box as seen in Figure 3.1. There is a front and back row of tubes consisting of 10 boron-lined tubes each. The front row and back row of tubes were individually connected to the electronics for readout. External electronics were used for the testing, as seen in Figure 3.2, since the SAIC electronics would not accept the signals produced by the GE Reuter Stokes system (due to pulse shape differences). A computer accumulated the spectra of proportional counter responses. A single ${ }^{3} \mathrm{He}$ tube in the SAIC moderator box was also measured as a comparison to the GE Reuter Stokes assembly.

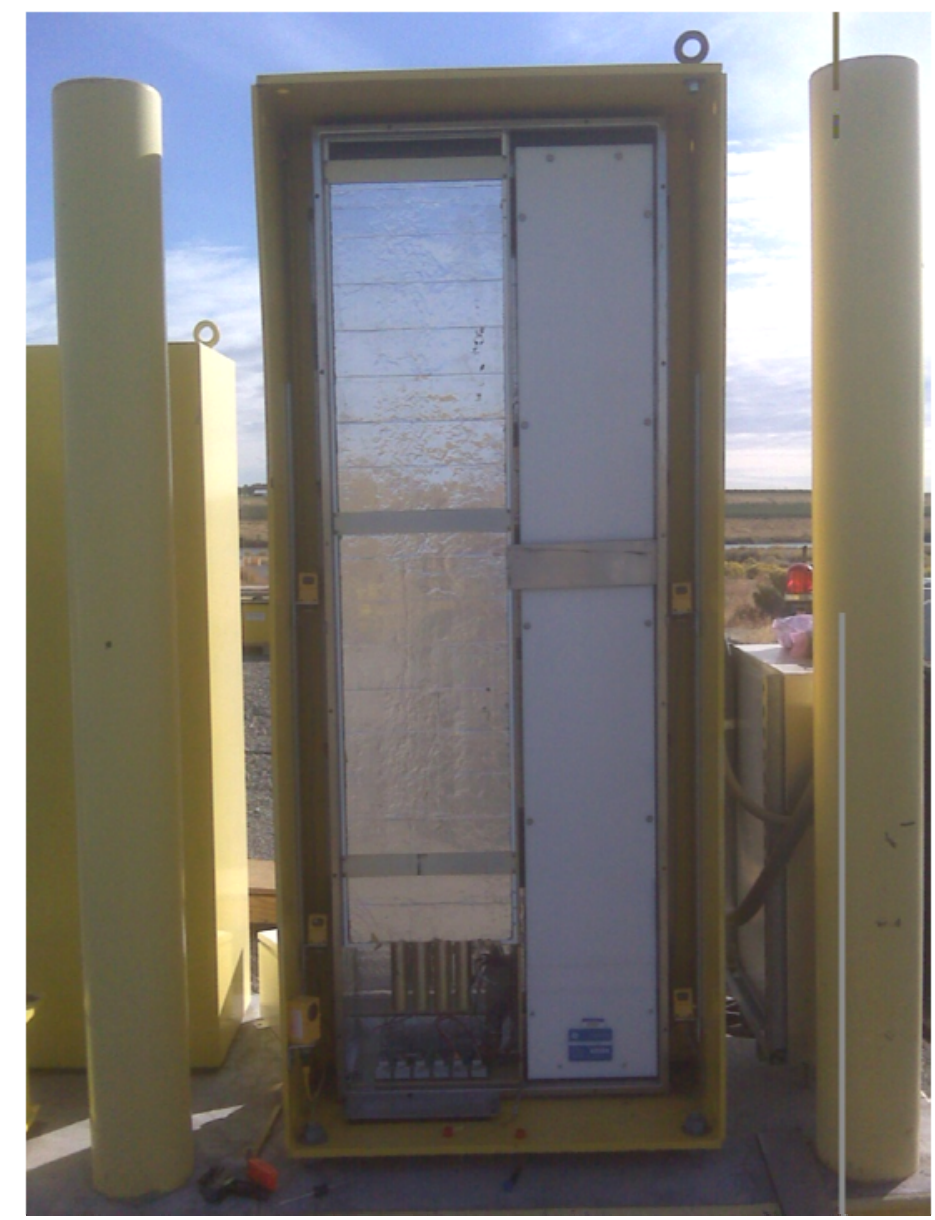

Figure 3.1: View of the GE Reuter Stokes detector (right side) in an RPM Radiation Sensor Panel. 


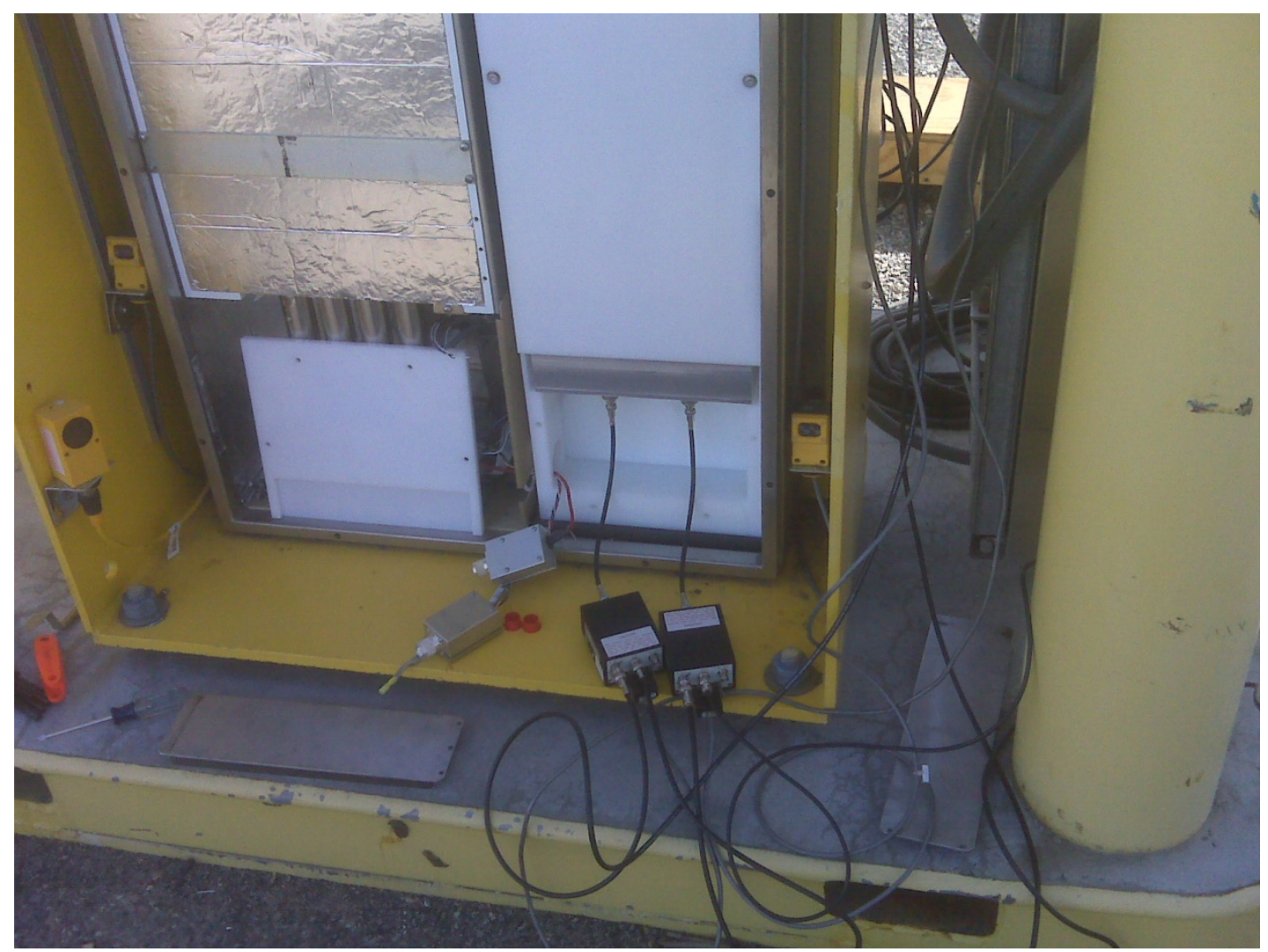

Figure 3.2: GE Reuter Stokes external detector electronics used in the testing.

\subsection{Neutron Source}

The neutron source used for this test was ${ }^{252} \mathrm{Cf}$ purchased from Isotope Products Laboratory (IPL) and given a PNNL ID of 60208-40D. The source was measured by IPL to be $20 \pm 3 \mu \mathrm{Ci}$ on June 5, 2009. The source composition was activities of $93.193 \%{ }^{252} \mathrm{Cf}, 0.0395 \%{ }^{251} \mathrm{Cf}, 6.635 \%{ }^{250} \mathrm{Cf}$, and $0.132 \%{ }^{249} \mathrm{Cf}$ according to IPL. From these isotopic contents, the source activity was estimated to be $18.5 \mu \mathrm{Ci}$ for this testing. However, cross-calibration with a NIST traceable ${ }^{252} \mathrm{Cf}$ source (PNNL ID 60208-44) yielded an activity of $20.3 \pm 1.2 \mu \mathrm{Ci}$. The activity of $20.3 \mu \mathrm{Ci}$ corresponds to an estimated emanation rate of $8.65 \times$ $10^{4} \mathrm{n} / \mathrm{s}$ using the conversion factor stated in Section 2.

The source was used in two configurations; 1$)$ moderated $(2.5 \mathrm{~cm}$ of polyethylene moderator outside of $0.5 \mathrm{~cm}$ of lead) and 2) bare (encased only in the stainless steel enclosure of the source). The source was placed on a tripod so that it was at the same height as the center of the detection unit.

\subsection{Gamma Source}

A ${ }^{60} \mathrm{Co}$ source was used for the gamma sensitivity tests. The exposure rate at the detector from the source was provided by the staff at Building 318. Due to the uncertainty in the original source strength and the varying degree of scatter contribution to the exposure rate at each position caused by the location of the source inside a room, the source activity on the day of the tests was determined by calculating what source strength would be necessary to deliver the exposure rate measured at each position. The distances for the various exposure rates were determined by PNNL staff and marked on the floor. 


\subsection{Test Facility}

The tests were performed at the $331 \mathrm{G}$ Integration Test Facility, and in the 318 Building in the High Energy Calibration Laboratory, both located at PNNL in Richland, WA. The static tests were performed on Thursday-Friday, October 1-2, 2009. The gamma insensitivity measurements with the ${ }^{60}$ Co source were performed on Wednesday, October 7, 2009. 


\section{Test Limitations}

There were several limitations for this test and results may change with different conditions.

- Only one test location was used for each test, with the corresponding background. Since the testing was focused on net results (background subtracted) this should have little effect on the overall results.

- Only one GE Reuter Stokes detector system was tested. Results may change with different detector designs.

- Uncertainty in the source strength was the main limitation to the test results. 


\section{Experiment Equipment and Setup}

\subsection{Electronics}

The GE Reuter-Stokes detector was designed to be a direct replacement for the currently deployed SAIC ${ }^{3}$ He neutron detection module. The GE Reuter-Stokes detector was able to be physically placed in the available space; however, the current SAIC electronics were unable to process the signal produced. The boron-lined tubes can be operated at a lower voltage than the ${ }^{3} \mathrm{He}$ tubes $(800 \mathrm{~V}$ vs. $1100 \mathrm{~V})$ but the capacitance of the GE Reuter-Stokes system was apparently too large for the SAIC pre-amps. Thus, external electronics were used to test the system. For these tests the ${ }^{3} \mathrm{He}$ tubes were also operated with the external electronics so that a direct comparison could be made between the two systems. The ${ }^{3} \mathrm{He}$ tubes were operated at $1100 \mathrm{~V}$ with the external electronics, a gain of 100 and a shaping time of $3 \mu$ seconds; the boron-lined tubes were operated at $800 \mathrm{~V}$, a gain of 10 and a shaping time of $1 \mu$ second for the static tests and $0.5 \mu$ seconds for the gamma insensitivity tests. The shorter shaping time decreased the neutron efficiency by approximately 9\% (as can be seen in Figure 6.3), but this decrease was accepted as the shorter shaping time also reduced the system response to gamma rays. The SAIC electronics would need to be slightly modified for this technology to be a replacement for what is currently deployed.

\subsection{Static Measurements}

Static measurements were made both with the original polyethylene moderator thickness $(12.7 \mathrm{~mm})$ as provide by GE Reuter Stokes and with an added $12.7 \mathrm{~mm}(0.5 \mathrm{inch})$ of moderation to the front of the detector. The detector system was situated both in the SAIC shroud (with and without the door) and outside of the shroud on a table (Figure 5.1). The neutron source was located on a tripod $2 \mathrm{~m}$ from the detector housing and at a height that positioned the source in the center of the detector for all of the tests. Measurements were made with neutron source positioned on both sides of the detector. Data were acquired over five minute intervals with the neutron source in the standard polyethylene pig ( $6 \mathrm{~mm}$ of lead and $25 \mathrm{~mm}$ of polyethylene) and bare.

The static measurements were used to obtain data that allowed the GE Reuter Stokes detector efficiency to be compared to the efficiency of one ${ }^{3} \mathrm{He}$ tube used in the current RPM systems. 


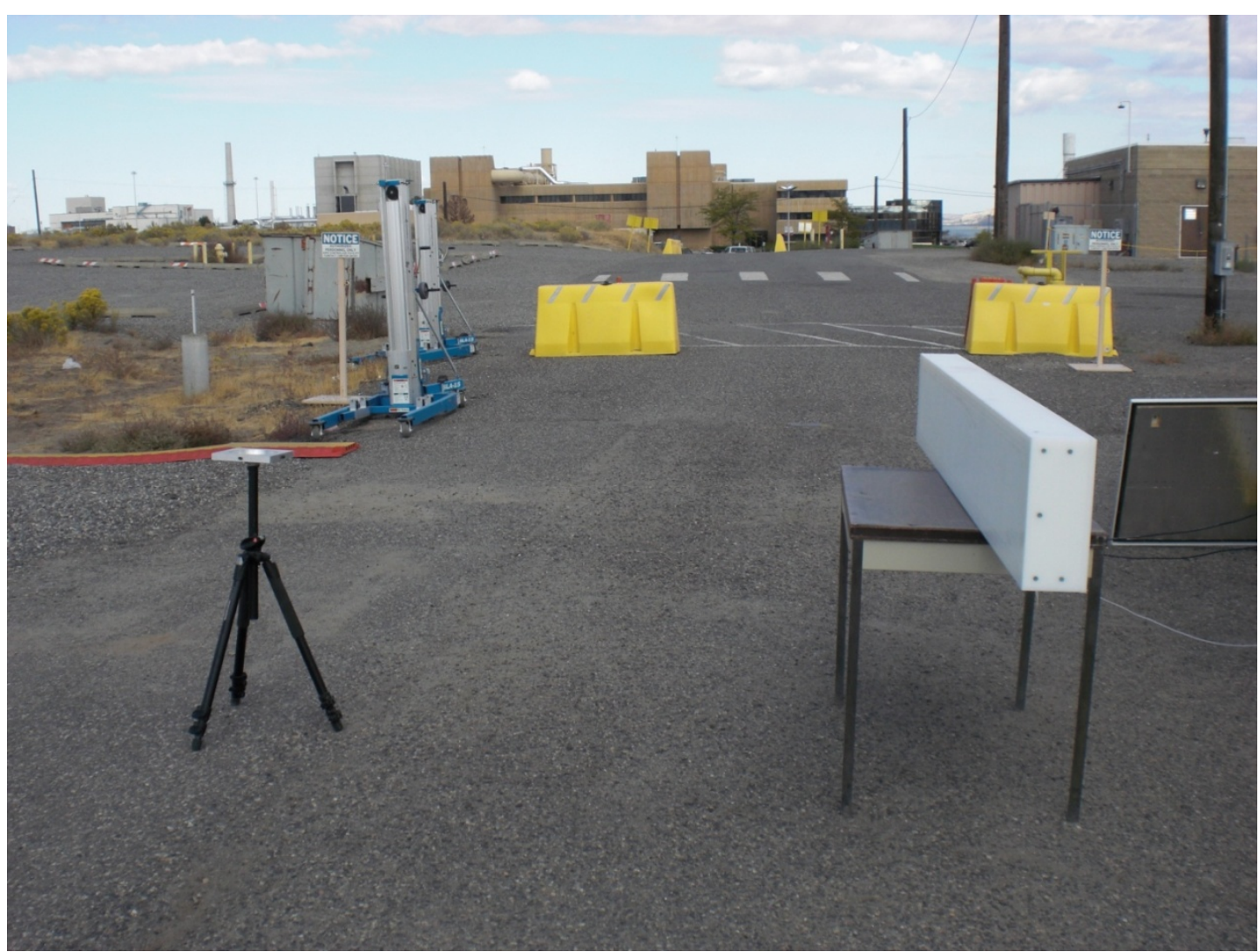

Figure 5.1: GE Reuter Stokes detector assembly positioned for static tests outside of the SAIC shroud.

\subsection{Gamma Insensitivity Measurements}

The detector sensitivity to gamma rays was tested with an intense ${ }^{60} \mathrm{Co}$ gamma-ray source. Tests were performed in the High Energy Calibration Laboratory in Building 318. Measurements were made with the gamma ray source by itself and with the gamma ray source used simultaneously with a neutron source placed $2 \mathrm{~m}$ from the back of the detector.

The detector (white polyethylene box in Figure 5.2) was moved different distances from the gamma ray source to obtain the desired exposure rates on the front face of the detector when the ${ }^{60} \mathrm{Co}$ source was shuttled into the end of the source tube (in the foreground of Figure 5.2). Table 5.1 gives the exposure rate versus distance for the gamma ray exposures. The neutron source was placed on the backside of the detector for simultaneous measurements (peaking above the detector at the back of the room in Figure 5.2) 


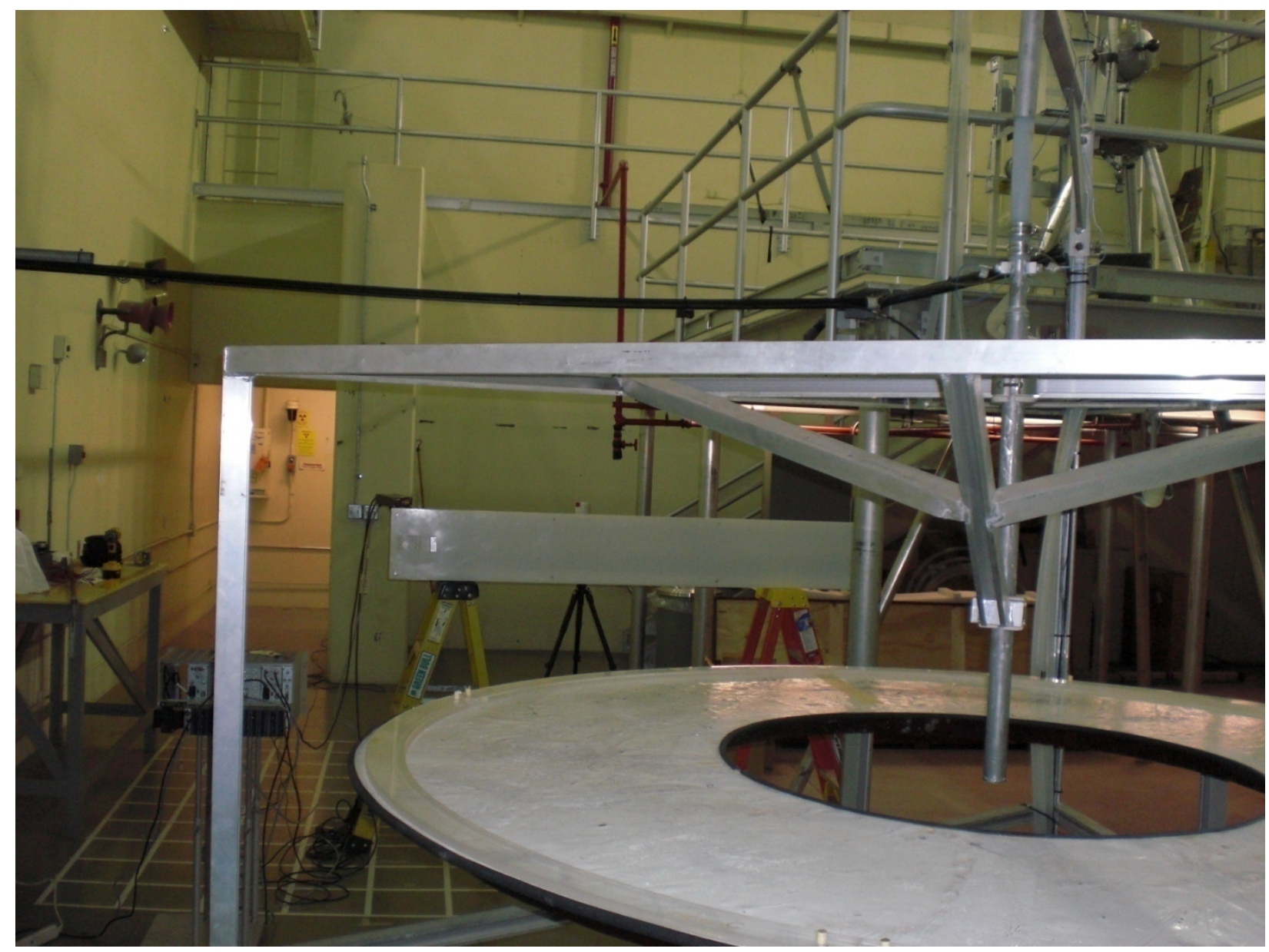

Figure 5.2: GE Reuter Stokes detector positioned for testing with the gamma ray and neutron sources.

Table 5.1: Exposure rate versus distance for the gamma ray source at Building 318.

\begin{tabular}{|c|c|}
\hline Exposure Rate (mR/h) & Distance (m) \\
\hline 10 & 3.88 \\
\hline 20 & 2.74 \\
\hline 30 & 2.24 \\
\hline 50 & 1.73 \\
\hline 70 & 1.47 \\
\hline 100 & 1.23 \\
\hline
\end{tabular}

Five-minute measurements were made for four different configurations at each position:

1. ${ }^{60}$ Co source closed (background)

2. ${ }^{60}$ Co source open

3. ${ }^{60} \mathrm{Co}$ source open and the neutron source located on a tripod $2 \mathrm{~m}$ from the back of the detector

4. ${ }^{60} \mathrm{Co}$ source closed and the neutron source located on a tripod $2 \mathrm{~m}$ from the back of the detector. 


\section{Results and Data Analysis}

\subsection{Modeling Results}

In related work, a MCNPX model study of a generic 2-inch diameter boron-lined tube was performed. The result of the model, seen in Figure 6.1(a), shows the proportional counter spectrum produced by the alpha and ${ }^{7} \mathrm{Li}$ particles leaving the wall of the tube. An energy threshold is set on this spectrum to count neutron interactions, where the threshold is determined by the value required to reject gamma ray pileup events when the detector is exposed to a $10 \mathrm{mR} / \mathrm{h}$ field. The alpha particles are emitted to an excited state and the ground state, leading to the shoulder at higher energy. This model result matches the experimentally observed spectrum from the multi-tube GE Reuter Stokes prototype (Figure 6.1(b)) quite well. Details on this work will be provided in a separate report.

\subsection{Static Test}

The data collected for the static measurements were used to determine the net count rate of the system and to estimate the absolute neutron detection efficiency. A lower level threshold was set for the data acquired with the external electronics to minimize the contribution from gamma rays. The channel for the lower threshold was set one channel above the highest channel affected by a ${ }^{60} \mathrm{Co}$ exposure rate of 10 $\mathrm{mR} / \mathrm{hr}$ (channel 12, note that the selected threshold would be appropriate up to $30 \mathrm{mR} / \mathrm{hr}$ ).

The front and back layers of detectors in the GE Reuter-Stokes system were read separately. Data from both layers were collected for 5 minutes in each of the static configurations. The data above the lower level threshold were summed for the two layers of detectors across all of the acquisition channels. The configuration-specific background was subtracted to determine the net count rate. The net count rate with the neutron source in both its bare and moderated form was measured with the detector system in the SAIC shroud, with the outer door both open and closed, and with additional front detector moderation, Figure 6.2. The uncertainty in the measurements is based on Poisson statistics and is less than the size of the plot symbols.

When the system was placed in the SAIC shroud the front layer of detectors recorded approximately $1 \%$ fewer neutrons per second than the back layer with the moderated source. With the unmoderated source the front layer recorded approximately $28 \%$ fewer neutrons per second. The lower neutron count rate recorded by the front layer indicates that the front layer of detectors is under-moderated. However, increasing the front moderation to $25.4 \mathrm{~mm}$ (doubling the original moderation thickness) resulted in approximately $16 \%$ fewer counts per second in the back layer than the front layer of detectors with the moderated source and a slight (less than $1 \%$ ) overall decrease in the net count rate. Thus, increasing the front moderation of this detector did not result in a net increase in the neutron detection efficiency. When the detector system was tested outside of the SAIC shroud the front layer of detectors recorded $4 \%$ more counts per second than the back layer. The front and back layer count rates for the system in and out of the SAIC shroud and in the SAIC shroud with added moderation are shown in Figure 6.3. The uncertainty in the measurements is less than the size of the plot symbols. 


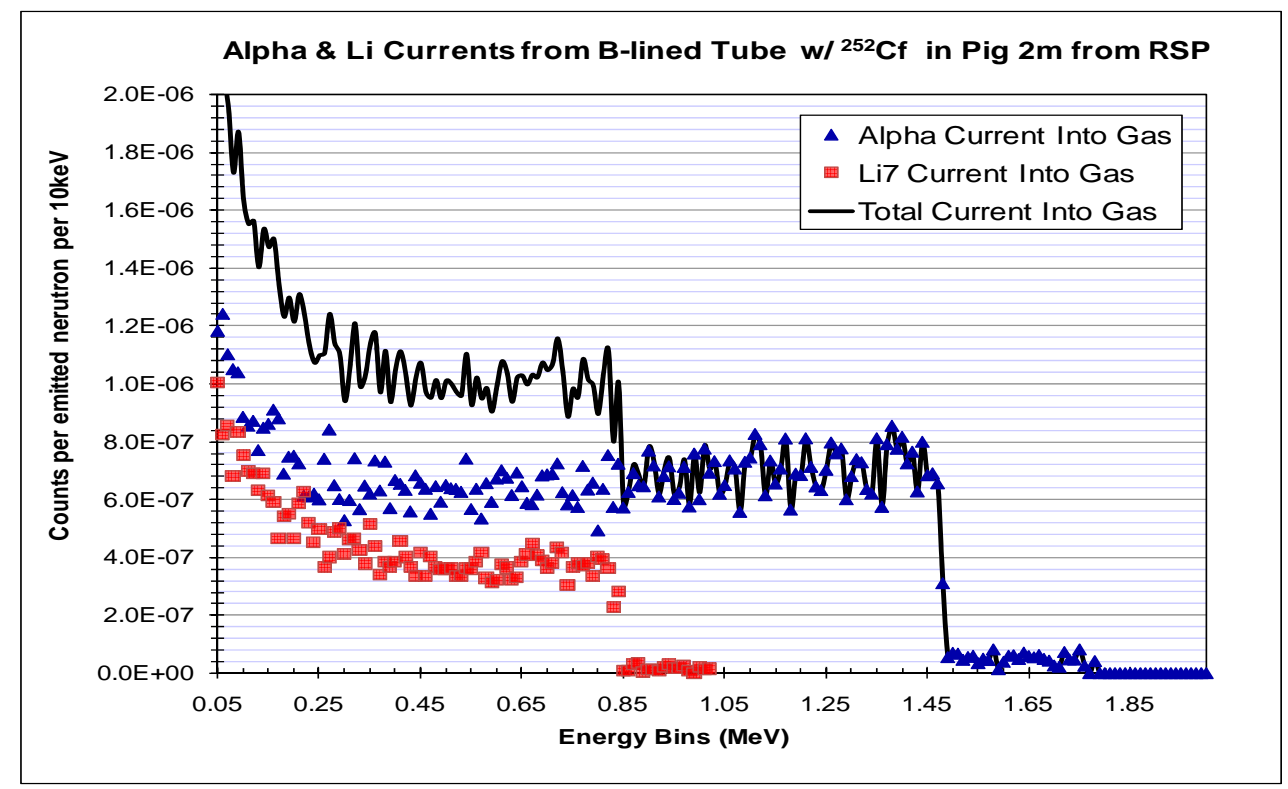

(a)

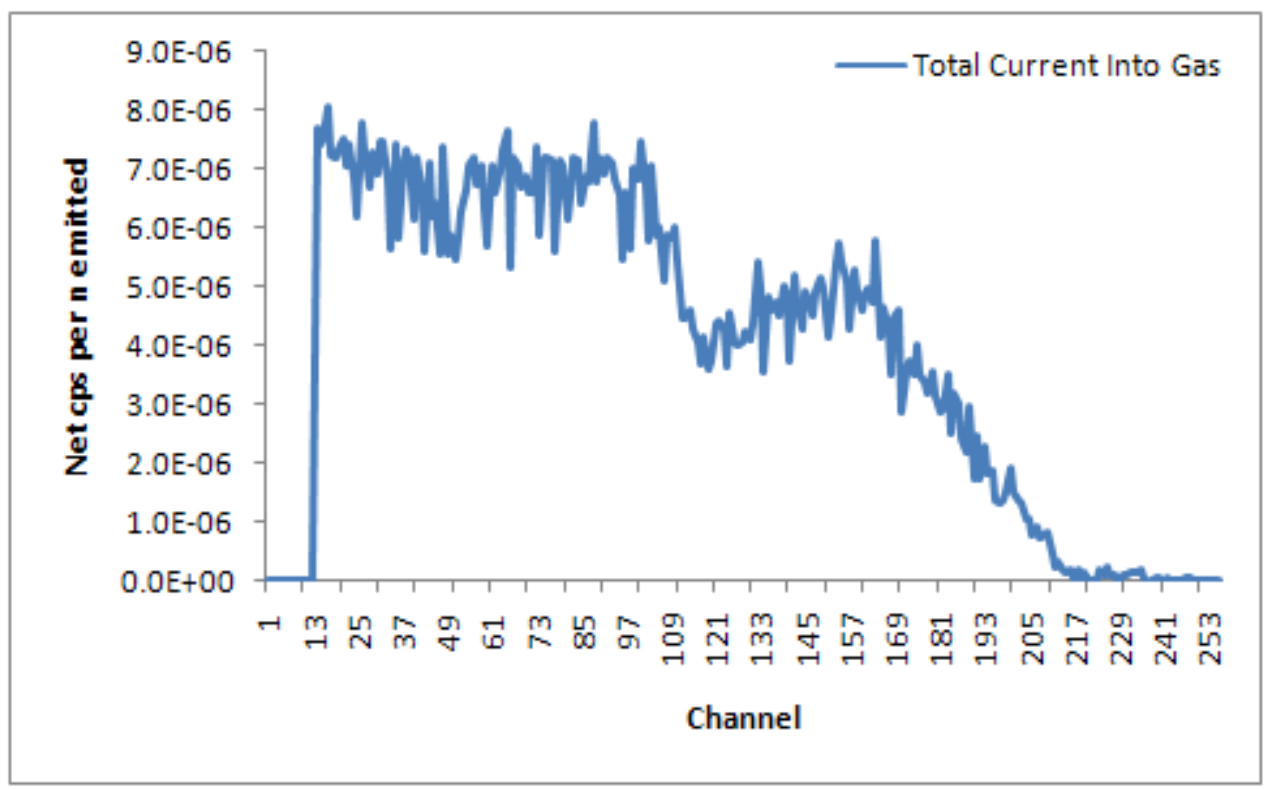

(b)

Figure 6.1: Modeling result (a) for response of a single two-inch diameter boron-lined tube to neutrons, and the experimental result for the response of the multi-tube GE Reuter Stokes prototype detector system (b). 


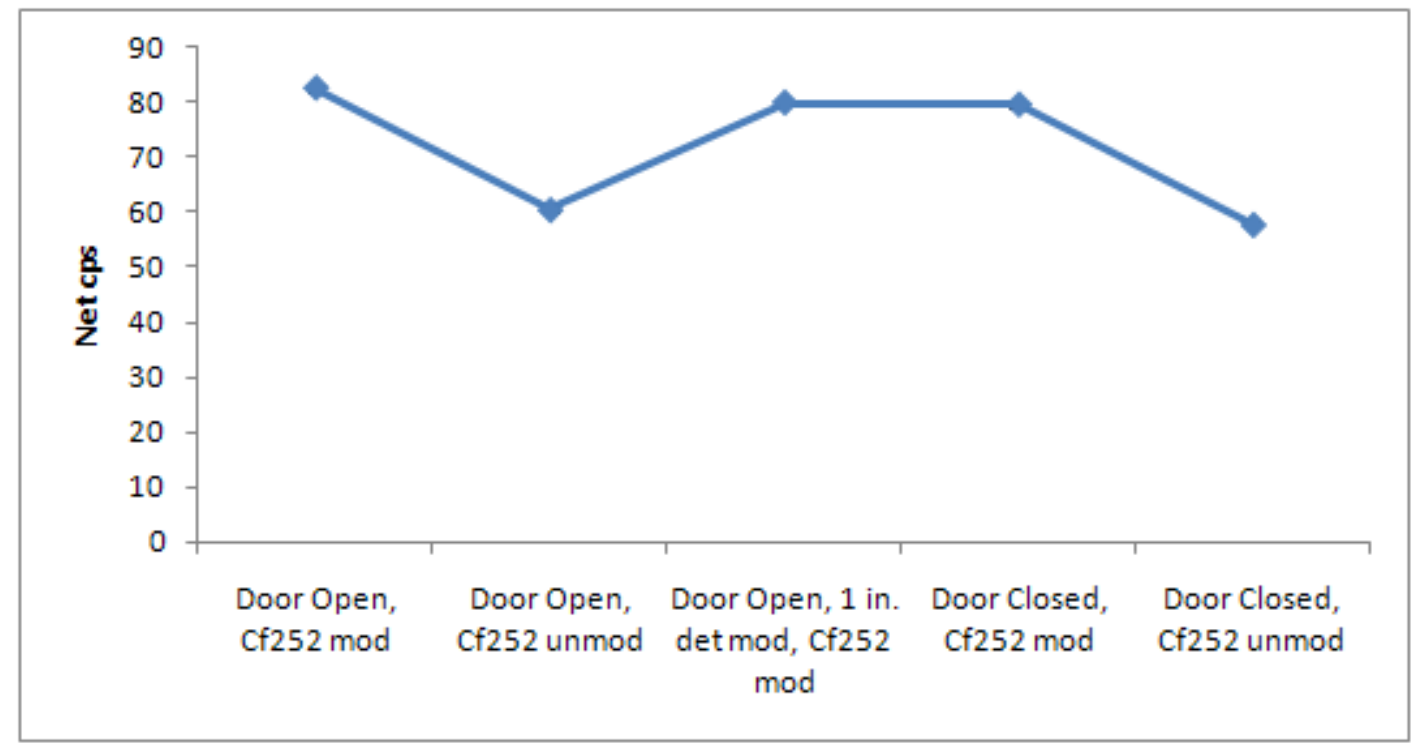

Figure 6.2: Count rate obtained with the GE Reuter-Stokes detector prototype.

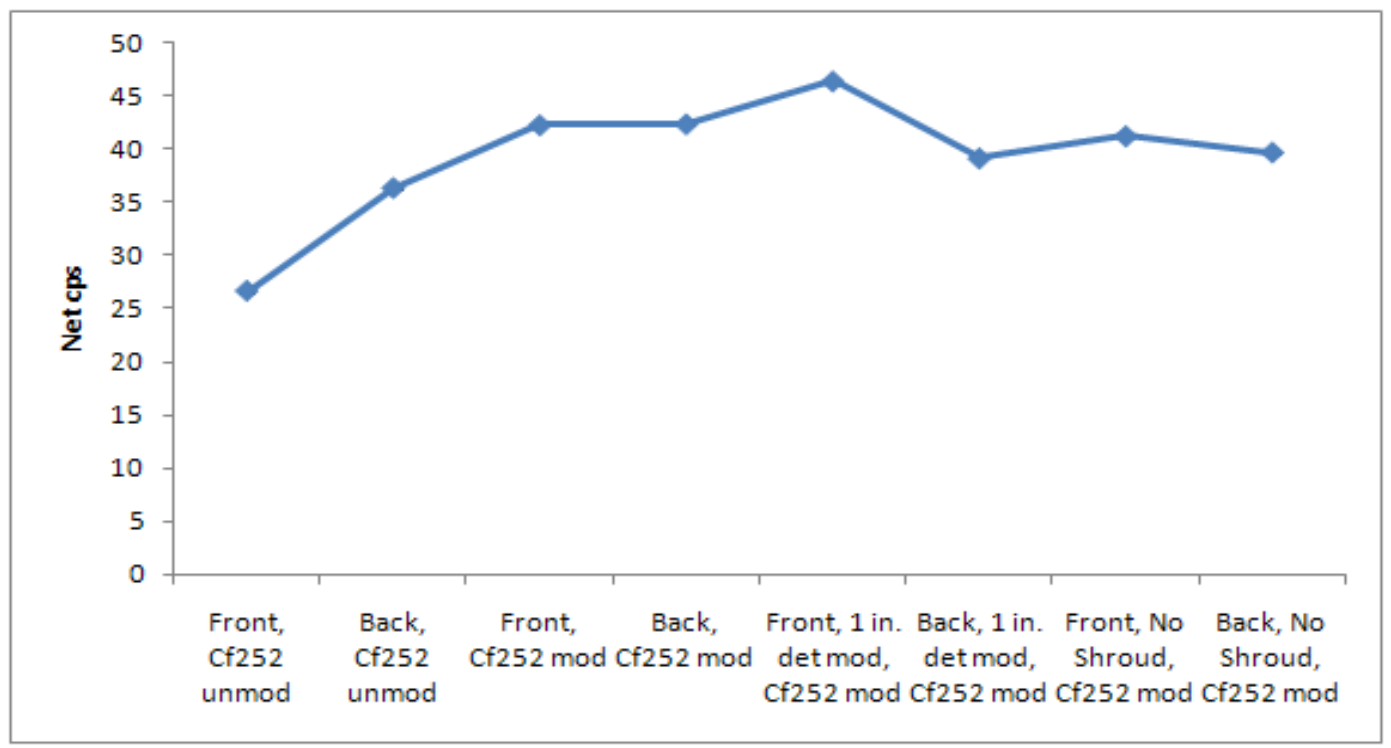

Figure 6.3: Net count rate obtained with the front and back layer of detectors for different test configurations with the moderated and bare source.

The absolute neutron efficiency of the boron lined tube detector system for the different configurations (including the different shaping times used) was estimated by dividing the sum of the net count rate from the front and back detector layers obtained with the moderated source by the material mass (in nanograms) of the ${ }^{252} \mathrm{Cf}$ source, Figure 6.4. The absolute neutron efficiency was compared to the efficiency of one ${ }^{3} \mathrm{He}$ tube in the SAIC moderator box and the required absolute neutron efficiency. The efficiency of the boron lined tube detector system is $2.12 \mathrm{cps} / \mathrm{ng}$ (in the SAIC shroud with the outer door on) which is $85 \%$ of the required $2.5 \mathrm{cps} / \mathrm{ng}$. The efficiency of one ${ }^{3} \mathrm{He}$ tube with the external electronics is $2.95 \mathrm{cps} / \mathrm{ng}$. The uncertainty of these calculations is $5.7 \%$ and comes mostly from the uncertainty in source strength. The actual uncertainty of the source strength provided by the vendor is $10 \%$, but this was reduced by cross-calibrating the source with a NIST traceable ${ }^{252} \mathrm{Cf}$ source with an uncertainty of $5.7 \%$. 


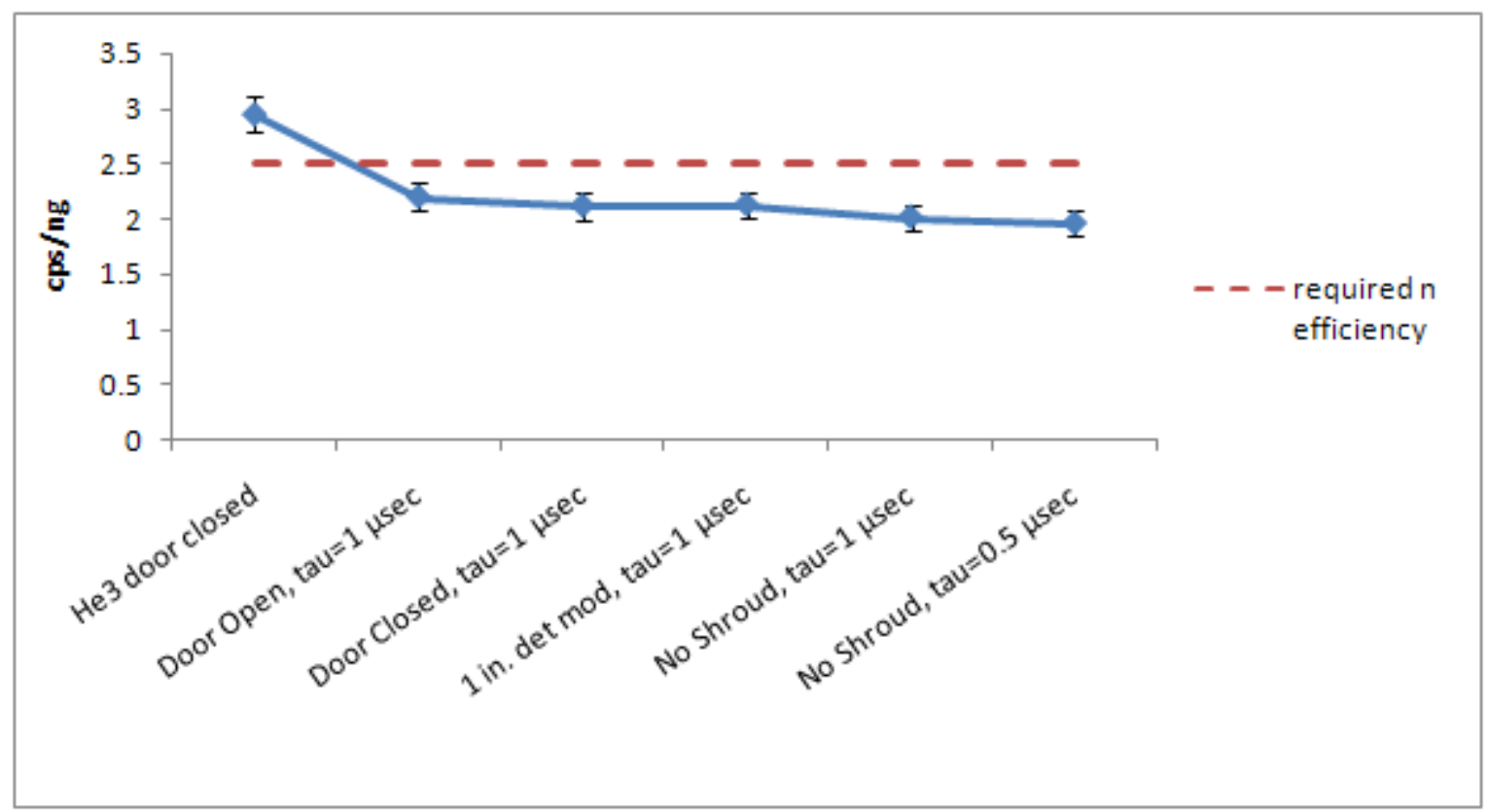

Figure 6.4: Neutron efficiency of the GE Reuter-Stokes detector system under different test scenarios compared to one ${ }^{3} \mathrm{He}$ tube in the SAIC polyethylene moderating box.

\subsection{Gamma Insensitivity Test}

The response of the boron-lined tubes to a high gamma exposure rate was evaluated with the ${ }^{60} \mathrm{Co}$ source at the High Energy Calibration Laboratory in Building 318. The detector system in its moderating box was positioned at specific distances from the source to achieve the desired exposure rate at the detector surface. Data were collected over 5 minute time intervals for the four test scenarios (background, ${ }^{60} \mathrm{Co}$, ${ }^{252} \mathrm{Cf}$, and ${ }^{60} \mathrm{Co}$ with ${ }^{252} \mathrm{Cf}$ ). The background was subtracted from all of the test results to provide the net count rate at each position. The data were collected with the external electronics configured to have a shaping time of $0.5 \mu$ seconds to minimize the effect of the gamma rays on the signal. With these settings there was minimal detector response to the gamma source above channel 13 (Figure 6.5) at exposure rates up to $100 \mathrm{mR} / \mathrm{hr}$. A ${ }^{3} \mathrm{He}$ tube in the SAIC moderating box was also tested with the external electronics and it can be seen, Figure 6.6, that the boron lined detectors exhibit slightly less response to gamma rays than the ${ }^{3} \mathrm{He}$ detectors over the exposure rates tested. The net count rates obtained with the boron lined tubes in the presence of different gamma ray field strengths are listed in Table 6.2.

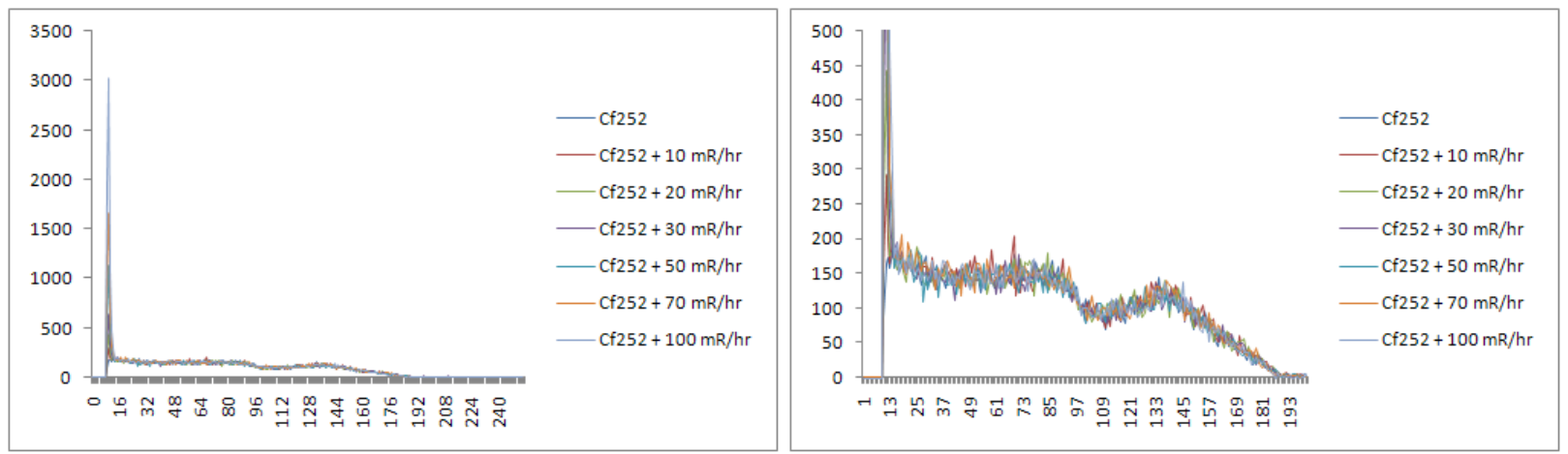

Figure 6.5: Response of boron lined tubes to ${ }^{60} \mathrm{Co}$ gamma rays on the left and scaled to show neutron detail on the right. 


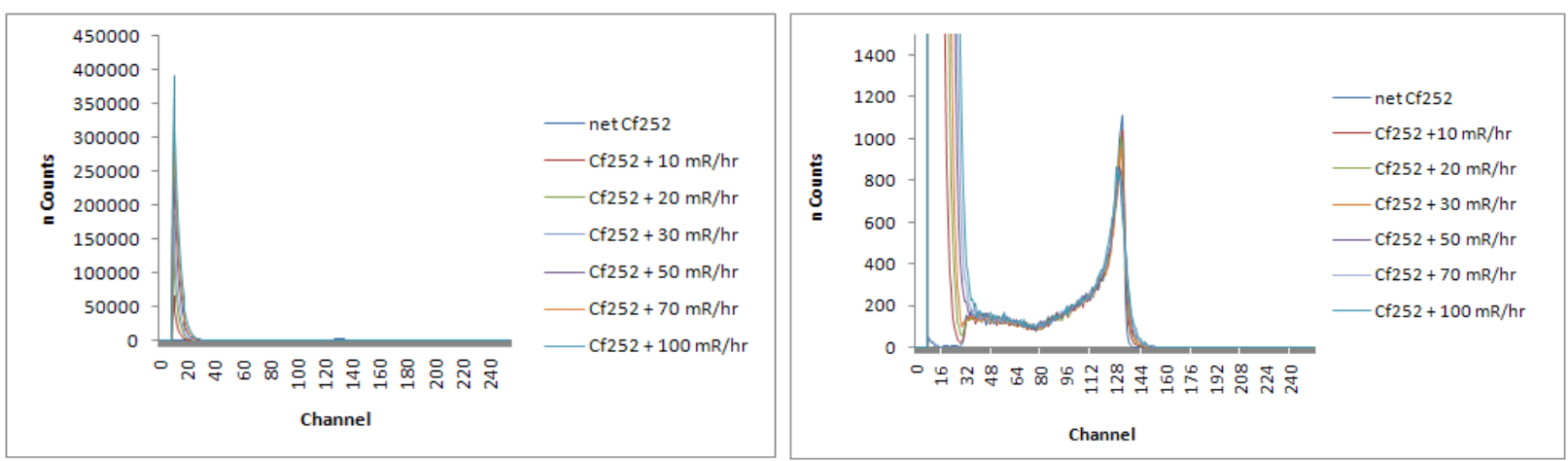

Figure 6.6: Response of ${ }^{3} \mathrm{He}$ tubes operated with external electronics to ${ }^{60} \mathrm{Co}$ gamma rays on the left and scaled to show detail on the right.

Table 6.1: Neutron counts recorded with the boron-lined tubes in the presence of high exposure gamma field.

\begin{tabular}{|c|c|c|c|c|}
\hline $\begin{array}{c}\text { Exposure } \\
\text { Rate } \\
(\mathrm{mR} / \mathrm{hr})\end{array}$ & $\begin{array}{l}\text { Neutron Counts } \\
\text { with only }{ }^{60} \mathrm{Co} \\
\text { Source (net cps) }\end{array}$ & $\begin{array}{c}{ }^{252} \text { Cf Source } \\
\text { Only } \\
\text { (net cps) }\end{array}$ & $\begin{array}{c}\text { Neutron Counts with } \\
{ }^{252} \mathrm{Cf} \text { and }{ }^{60} \mathrm{Co} \\
\text { Sources (net cps) }\end{array}$ & $\begin{array}{c}\left({ }^{252} \mathrm{Cf} \text { Source) minus }\right. \\
\left({ }^{252} \mathrm{Cf} \&{ }^{60} \mathrm{Co} \text { Sources }\right) \\
(\text { net cps) }\end{array}$ \\
\hline 10 & $-0.15(13)$ & $65.7(5)$ & $66.8(5)$ & -1.1 \\
\hline 20 & $0.16(14)$ & $65.7(5)$ & $66.4(5)$ & -0.7 \\
\hline 30 & $0.17(14)$ & $65.7(5)$ & $64.8(5)$ & 0.9 \\
\hline 50 & $0.03(13)$ & $65.7(5)$ & $64.8(5)$ & 0.9 \\
\hline 70 & $0.07(14)$ & $65.7(5)$ & $66.8(5)$ & -1.1 \\
\hline 100 & $0.50(14)$ & $65.7(5)$ & $66.3(5)$ & -0.6 \\
\hline
\end{tabular}

An approximate value for the intrinsic gamma ray efficiency and GARRn can be calculated using the counts recorded in Table 6.2 and the estimated gamma flux at the detector.

\section{Gamma Flux Estimate}

The exact source strength of the ${ }^{60} \mathrm{Co}$ source used to make the gamma insensitivity measurements was not known so the photon flux at the detector surface was determined by use of the measured exposure rate, shown in Table 6.3. It should be noted that the measurements were made indoors and the contribution of scatter to the measured exposure rate increased with increasing distance from the source. The measured exposure rate was used to develop an estimate of the source strength and to account for the scatter contribution. The gamma factor for ${ }^{60} \mathrm{Co}$ used to determine the number of photons incident on the detector face for a given exposure rate was $13.2 \mathrm{R} \cdot \mathrm{cm}^{2} / \mathrm{hr} \bullet \mathrm{mCi}$.

Table 6.2: Estimated number of photons incident on the active area of the detector calculated with both the source strength and an effective activity for each of the exposure rates.

\begin{tabular}{|c|c|c|c|}
\hline $\begin{array}{c}\text { Exposure Rate } \\
(\mathbf{m R} / \mathbf{h r})\end{array}$ & $\begin{array}{c}\text { Detector to } \\
\text { Source Distance } \\
(\mathbf{m})\end{array}$ & $\begin{array}{c}\text { 'Effective' Source } \\
\text { Activity (Ci) }\end{array}$ & $\begin{array}{c}\text { Estimated } \\
\text { Photons on } \\
\text { Detector From } \\
\text { Effective Activity } \\
\text { (cps) }\end{array}$ \\
\hline 10 & 3.88 & 0.114 & $3.00 \mathrm{E}+07$ \\
\hline 20 & 2.74 & 0.114 & $6.02 \mathrm{E}+07$ \\
\hline 30 & 2.24 & 0.114 & $9.01 \mathrm{E}+07$ \\
\hline 50 & 1.73 & 0.113 & $1.51 \mathrm{E}+08$ \\
\hline 70 & 1.47 & 0.115 & $2.09 \mathrm{E}+08$ \\
\hline 100 & 1.23 & 0.115 & $2.99 \mathrm{E}+08$ \\
\hline
\end{tabular}


The gamma insensitivity estimates were made by using the estimated photon flux on the detector to determine the rate at which gamma rays were miscounted as neutrons. The GARRn was calculated by taking the ratio of the absolute neutron efficiency with no gamma source present (Table 6.3, column two, row one) to the absolute neutron efficiency with the gamma source present (Table 6.3, column two, rows two-seven). The absolute neutron efficiency both with and without the gamma source was measured with the neutron source located on the back side of the detector in cps (the same configuration as used in the gamma insensitivity tests). The geometry specific absolute neutron efficiency was used so that the neutron source was in the same position for the neutron efficiency measurements made with and without gamma ray source present, thus eliminating any geometry effects on GARRn.

\section{Table 6.3: Estimates of the Absolute Efficiency, GARRn and the Intrinsic Gamma Ray Rejection Factor for} the different gamma exposure rates.

\begin{tabular}{|c|c|c|c|}
\hline $\begin{array}{c}\text { Exposure } \\
\text { Rate } \\
(\mathbf{m R} / \mathbf{h r})\end{array}$ & $\begin{array}{c}\text { Neutron } \\
\text { Efficiency } \\
\mathbf{\epsilon}_{\mathbf{n}}(\mathbf{n} / \mathbf{s})\end{array}$ & $\begin{array}{c}\text { Intrinsic Gamma Ray } \\
\text { Efficiency } \\
\mathbf{\epsilon}_{\text {int } \mathbf{~} \mathbf{n}}\end{array}$ & $\begin{array}{c}\text { GARRn } \\
\mathbf{\epsilon}_{\text {abs } \mathbf{~} \mathbf{n}} / \mathbf{\epsilon}_{\mathbf{n}}\end{array}$ \\
\hline 0 & $7.60 \mathrm{E}-4$ & $1.52 \mathrm{E}-06$ & - \\
\hline 10 & $7.72 \mathrm{E}-4$ & $8.06 \mathrm{E}-07$ & $1.02(1)$ \\
\hline 20 & $7.68 \mathrm{E}-4$ & $5.61 \mathrm{E}-07$ & $1.01(1)$ \\
\hline 30 & $7.50 \mathrm{E}-4$ & $4.97 \mathrm{E}-08$ & $0.99(1)$ \\
\hline 50 & $7.50 \mathrm{E}-4$ & $1.03 \mathrm{E}-07$ & $0.99(1)$ \\
\hline 70 & $7.73 \mathrm{E}-4$ & $5.01 \mathrm{E}-07$ & $1.02(1)$ \\
\hline 100 & $7.67 \mathrm{E}-4$ & & $1.01(1)$ \\
\hline
\end{tabular}

The measured GARRn values are well within the window specified $(0.9<$ GARRn $<1.1)$ for an exposure rate of $10 \mathrm{mR} / \mathrm{hr}$. The intrinsic efficiency meets the required $10^{-6}$ at $10 \mathrm{mR} / \mathrm{hr}$ (there is a possible trade off of neutron detection efficiency and this gamma insensitivity efficiency). It should be noted that both the intrinsic efficiency and GARRn have acceptable values for all of exposure rates tested. Thus, with the lower limit threshold selected, gamma rays do not appear to have a strong effect on the boron lined tubes. 


\section{Conclusions}

The first prototype GE Reuter-Stokes boron-lined tube neutron detector system was tested and compared to the currently deployed ${ }^{3} \mathrm{He}$ neutron detection system as a possible alternative neutron detection technology. The boron-tubes detect neutrons when the charged particles from the ${ }^{10} \mathrm{~B}(\mathrm{n}, \alpha)^{7} \mathrm{Li}$ reaction react with the fill gas in the proportional counter. The GE Reuter-Stokes prototype was designed to fit in the currently deployed SAIC system but external electronics had to be used to read out the signal because the SAIC pre-amps were not designed to function with the high capacitance of the GE Reuter-Stokes system.

The results suggest that improving the neutron efficiency of the system by $\sim 40 \%$ would result in a system that would have the same neutron efficiency as one ${ }^{3} \mathrm{He}$ tube in the SAIC moderating box. The gamma rejection capability of the GE Reuter-Stokes system is on the order of $10^{-6}$ at an exposure rate of 10 $\mathrm{mR} / \mathrm{hr}$ from a ${ }^{60} \mathrm{Co}$ source, which is the required value. This system was tested up to exposure rates of $100 \mathrm{mR} / \mathrm{hr}$ and its gamma rejection capability met the requirement at all the exposure rates. The GARRn value met the requirement of $0.9<$ GARRn $<1.1$ at an exposure rate of $10 \mathrm{mR} / \mathrm{hr}$. The GARRn value for this system was within the desired window for all of the gamma exposure rates tested, which indicates that the system does neither miscounts gammas as neutrons at high gamma exposure rates nor experiences a large dead time due to the presence of the gamma rays.

The boron-lined tubes can be operated at a lower voltage than the ${ }^{3} \mathrm{He}$ tubes so if the SAIC electronics are optimized to accommodate the higher system capacitance the GE Reuter-Stokes system would have the potential to be a drop-in replacement technology. The software would likely require some modification to account for the difference in pulse shape. 


\section{References and Bibliography}

ANSI. 2004. American National Standard for Evaluation and Performance of Radiation Detection Portal Monitors for Use in Homeland Security. Technical Report. ANSI 42.35, American Nuclear Standards Institute, Washington, D.C.

ASP. 2006. U.S. Department of Homeland Security Domestic Nuclear Detection Office (DNDO), Performance Specification for an Advanced Spectroscopic Portal (ASP), DNDO-PS-100220v2.20, March 15, 2006.

Ely J, Kouzes RT, Lintereur A, Schweppe J, Siciliano E, and Woodring M. 2009. BF 3 Neutron Detector Testing and Comparison to ${ }^{3} \mathrm{He}$. PNNL-18581, Pacific Northwest National Laboratory, Richland, WA.

Ely J, D Stromswold, and C Shepard. 2003. Radiation Portal Monitor Measurements. PIET-43741-TM014, PNNL-14110, Pacific Northwest National Laboratory, Richland, Washington.

Kouzes RT, Ely J, Lintereur A, Stephens D. 2009. Neutron Detector Gamma Insensitivity Criteria. PNNL-18903, Pacific Northwest National Laboratory, Richland, Washington.

Ely J and C Shepard. 2004. Test and Evaluation of the SAIC/Exploranium RPM8 Portal Monitor System. PIET-43741-TM-161, PNNL-16865, Pacific Northwest National Laboratory, Richland, WA.

HPS 2009. Accessed at http://hpschapters.org/northcarolina/nuclide_information_library September 2009.

ISO-8529. 1989. International Organization for Standardization 8529.

Kiernan G. 2003. Gerald Kiernan to Todd Hoffman, "Gamma and Neutron Sources for Use at Land Border, Seaport, and Airport Venues (U)," classified (SNSI) second guidance document from DOE/NA22, February 28, 2003 (PNNL received a copy of this document on June 17,2003). Update of DOE guidance document to CBP of September 19, 2002.

Knoll GF. 2002. Radiation Detection and Measurement $3^{\text {rd }}$ Ed. John Wiley and Sons, New York.

Kouzes RT, J Ely, and E Siciliano. 2007. Neutron Alarm Algorithms for Deployed RPMs. PIET-43741TM-663, PNNL-17101, Pacific Northwest National Laboratory, Richland, Washington.

Kouzes, RT, JH Ely, PE Keller, RJ McConn, and ER Siciliano. 2008. "Passive Neutron Detection for Interdiction of Nuclear Material at Borders." Nuclear Instruments and Methods in Physics Research Section A: Accelerators, Spectrometers, Detectors and Associated Equipment 584(2-3): 383-400.

Kouzes RT, ER Siciliano. 2009. ${ }^{3}$ He Neutron Detector Modification and BF $F_{3}$ Comparison. PIET-43741TM-838, PNNL-xxx, Pacific Northwest National Laboratory, Richland, Washington.

Kouzes, RT, 2009. “The ${ }^{3}$ He Supply Problem,” Pacific Northwest National Laboratory Report PNNL18388.

MCNP. 2003. MCNP X-5 Monte Carlo Team, MCNP - A General Purpose Monte Carlo N-Particle Transport Code, Version 5, LA-UR-03-1987, Los Alamos National Laboratory, April 2003. The MCNP code can be obtained from the Radiation Safety Information Computational Center (RSICC), P.O. Box 2008, Oak Ridge, TN, 37831-6362.

NNDC. National Nuclear Data Center. Accessed June 12, 2009 at http://www.nndc.bnl.gov/index.jsp.

Stromswold D, J Ely, R Kouzes, J Schweppe. 2003. Specifications for Radiation Portal Monitor Systems Revision 6.7. PIET-43741-TM-017, Pacific Northwest National Laboratory, Richland, Washington.

Van Ginhoven, RM, RT Kouzes, DL Stephens, 2009. “Alternative Neutron Detector Technologies for Homeland Security,” Pacific Northwest National Laboratory Report PNNL-18471. 


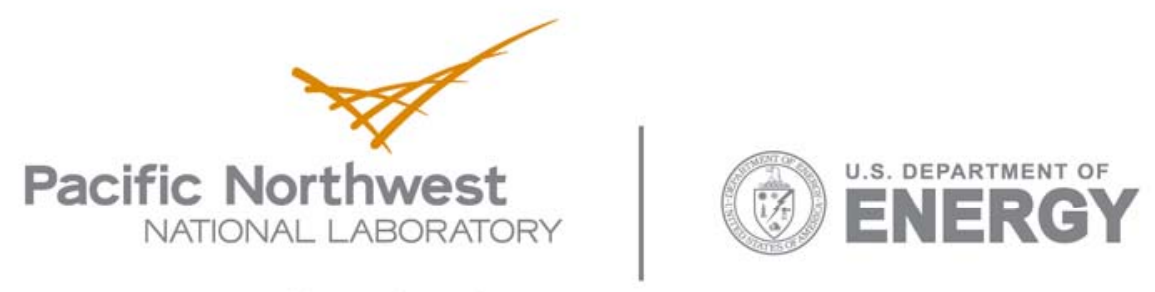

902 Battelle Boulevard

P.O. Box 999

Richland, WA 99352

1-888-375-PNNL (7665)

www.pnl.gov 